\title{
Evolving therapies for Peyronie's disease: how can we work towards new drugs?
}

\author{
Uros Milenkovic $^{1,2}$, Jolien Duponselle ${ }^{1}$, Trinity J. Bivalacqua ${ }^{3}$, Maarten Albersen ${ }^{1,2}$ \\ ${ }^{1}$ Laboratory of Experimental Urology, Department of Development and Regeneration, University of Leuven, Leuven, Belgium; ${ }^{2}$ Department of \\ Urology, University Hospitals of Leuven, Leuven, Belgium; 'James Buchanan Brady Urological Institute and Department of Urology, Johns Hopkins \\ School of Medicine, Baltimore, MD, USA \\ Contributions: (I) Conception and design: U Milenkovic, M Albersen; (II) Administrative support: U Milenkovic, J Duponselle, TJ Bivalacqua; \\ (III) Provision of study materials or patients: None; (IV) Collection and assembly of data: U Milenkovic, J Duponselle; (V) Data analysis and \\ interpretation: U Milenkovic; (VI) Manuscript writing: All authors; (VII) Final approval of manuscript: All authors. \\ Correspondence to: Prof. Maarten Albersen. Department of Urology and Laboratory of Experimental Urology, Catholic University and University \\ Hospitals Leuven, Herestraat 49, 3000 Leuven, Belgium. Email: maarten.albersen@uzleuven.be.
}

\begin{abstract}
Peyronie's disease (PD) is an idiopathic chronic fibrotic disease that causes a penile curvature (PC), subsequent erectile dysfunction (ED) and impaired sexual intercourse in patients. As of yet, there are no reliable non-surgical treatment options available. Intralesional injection with collagenase Clostridum Histolyticum has been FDA approved since 2013, but post-approval studies have not been unanimously positive. Moreover, it renders a curvature improvement of only $30 \%$ on average, usually still requiring surgical intervention to remedy PC. Therefore, there is a need for drugs which could prevent surgery altogether. Development of new drugs can either be through a target-based or phenotypic assay-based approach. The current in vivo model for PD is dependent on treatment of primary PD-derived fibroblasts with transforming growth factor- $\beta 1$. Moreover, despite the existence of a genetic in vivo PD model, it does not allow for drug screening or testing. While some advances have been made in the past few years, new in vivo and in vivo systems and well-designed studies are urgently needed for the non-surgical treatment of PD.
\end{abstract}

Keywords: Peyronie's disease (PD); fibrosis; injection therapy; medical treatment; drug development

Submitted May 02, 2019. Accepted for publication Jul 10, 2019.

doi: $10.21037 /$ tau.2019.08.09

View this article at: http://dx.doi.org/10.21037/tau.2019.08.09

\section{Introduction}

Peyronie's disease (PD) can be described as an idiopathic, chronic inflammatory and fibrotic disease affecting the connective tissue sheath [tunica albuginea (TA)] surrounding the erectile apparatus [corpora cavernosa (CC)]. Following an often painful, active, inflammatory phase, there is a chronic, "quiescent" state, where the pain subsides, but a curvature of the penis $\left(20-100^{\circ}\right)$ remains (1). This primarily leads to impaired sexual intercourse (due to aberrant anatomy) and erectile dysfunction (ED), the latter occurring in approximately $50 \%$ of the patients $(2,3)$. Additionally, aside from physical consequences, there is a significant psychological burden as well. Patients have lowered self-esteem and body image, and there is partner dissatisfaction and relationship difficulties due to PD. It has been shown that nearly $50 \%$ of PD patients develop clinically significant depression due to the disease (4). Despite extensive fundamental and clinical research in the past decade, medical treatments for PD are still lackluster. The most widely accepted hypothesis in the contemporary literature on pathophysiology postulates that PD is caused by (repetitive) "trauma" to the erect penis during intercourse (5). This mechanical stress would then cause the activation of latent transforming growth factor- $\beta 1$ (TGF- $\beta 1$ ) from the extracellular matrix (ECM) and fibrinogen extravasation (6). Fibrinogen is ultimately cleaved by thrombin to form fibrin. Both TGF- $\beta 1$ and 
fibrin are potent inducers of the inflammatory cascade by stimulation of chemotaxis, migration of macrophages (MФ) and monocytes and causing fibroblast (FB)-to-myofibroblast (MFB) transformation. However, to date, only the role of the $(\mathrm{M}) \mathrm{FB}$ and ECM have been extensively described and studied in PD (1,7-9). Moreover, previously studied oral and intralesional therapies have predominantly targeted this MFB transformation or break-down of ECM $(1,10-12)$. The only FDA/EMA-approved therapy remain injections of collagenase Clostridium bistolyticum $(\mathrm{CCH})$ and its usage and popularity have been mainly based on 2 large randomized trials (IMPRESS I and II) (13). However, post-FDA studies have tempered our enthusiasm due to high patient dropout, dissatisfaction and adverse events (14). Thus, the search for discovery of new medical (non-surgical) treatment options is certainly a quest that must not be abandoned.

In this review we will briefly explore the fibrotic process in PD, different in vivo modalities that have been applied over the past decades to study the molecular aspects of PD, available in vivo models and potential for novel treatment options.

\section{Prolonged wound healing leads to fibrosis}

The survival of a species can span several thousands of years, mainly by acquiring essential natural resources and reproducing. However, these resources tend to be scarce and limited, and individuals (or entire populations) need to compete with others in order to survive. Competition, both in social and non-social species, often leads to asserting some form of physical aggression, which usually causes tissue damage in both the "aggressor" and "defender". Thus, the ability of an individual to heal the damage from its hostile surroundings/predators is a quintessential component of survival (15). Response to damage, inflammation and wound healing are initiated by the innate immune system (16). The innate immune system exists to offer detection of and rapid protection against pathogen attack. Our wound healing has evolved in such a way that initial damage detection and repair is fast, efficient and similar across different tissues, but alas far from perfect. As such, most tissues in the human adult are not fully restored to its original function after sufficient damaging. For example, heavily burnt skin does not contain sweat glands or hair follicles, non-functional myocardial tissue stabilizing the heart after a severe myocardial infarction does not beat/pump blood around the body, damaged lung tissue does not exchange oxygen and carbon dioxide and scarred kidneys do not filter the blood sufficiently (6). This leads to the development of diseases due to altered or reduced function. Additionally, the need for rapid repair often makes the activation of inflammatory responses excessive. In case of delayed or failing terminative signals, this leads to fibrosis (17). Therefore, fibrosis can be attributable to chronic tissue injury, persisting signals for fibrogenesis and excessive deposition of ECM (18-20).

Fibrosis can primarily be defined as a disturbed state of wound repair and is the end-stage response to chronic tissue injury. There is a persevering immune response, inflammation and ensuing disproportionate deposition of collagens, elastin, fibronectin, proteoglycans, and other extracellular connective tissue proteins-this collection of proteins forming a dense 3D structure are termed the ECM $(21,22)$. Even though this inflammation and ECM formation are normal processes in regular wound healing, if the initial injury (mechanical stress, auto-antibodies or infection) is not removed in time, this process becomes dysregulated and leads to fibrosis $(18,23)$.

\section{Traversing the treatment gap in PD}

Over the past decades, surgery has become obsolete for certain non-malignant conditions such as duodenal ulcers, due to the discovery of their disease mechanism (24). However, despite being known for over 250 years, this still has not been the case for PD. Not in the least due to the fact that surgical methods are able to restore the most pressing anatomical problem (but without tackling the underlying disease), together with an underestimation of its prevalence and overestimation of the efficacy of injection therapies. Owing to this, the overall scientific motivation for etiological and pathophysiological studies has only known a slight increase during the past few years. Most notably this includes the development of an animal model [first in 1997 by El-Sakka et al. $(25,26)$ ], in vivo cell culture models (8,27-31) and extrapolation of what is known from the pathophysiology of other fibrotic diseases, such as cardiovascular, kidney, liver fibrosis and fibrosis associated with burn wounds (32-35).

Even though PD is a relatively common and devastating disorder [about $1-9 \%$ in the general population and $20-54 \%$ in the diabetic or post-prostatectomy population $(36,37)]$, it remains an affliction where relatively little attention is being given to in the public eye and more importantly, investment-wise. One can think of several reasons for this discrepancy. First, it is a non-lethal disease 
occurring frequently at older age (50-55 years old). Second, there is still a large stigma on talking about sexual health and related disorders. This is evidenced by a survey of the British Dupuytren's Society in 185 patients with PD. About $25 \%$ of men were no longer sexually active and $10 \%$ of the patients report to have their relationship ended due to the disease. A further $20 \%$ said they feel they will be laughed at if talking about it (38). Third, we can speculate that due to the existence of drugs such as CCH for PD, PDE5i for ED and the readily available (sometimes industry driven) surgical approaches, such as erectile prosthesis devices, there has been an underestimation of the treatment gap (due to a perception of risk bias) in PD and therefore a lack of investments in basic research and development of novel drugs.

A recent systematic review by Russo et al. (10) assessed the efficacy and scientific legitimacy for the use of different injection and mechanical therapies in PD. This revealed that current evidence shows that, out of seven therapies investigated, only $\mathrm{CCH}$ and interferon $\alpha-2 \mathrm{~B}$ (IFN $\alpha-2 \mathrm{~B})$ result in reductions of penile curvature (PC) (resp. ca. 30\% and $20 \%$ ) (other medications examined included calcium channel blockers, hyaluronic acid, onabotulinum toxin A, thiocolchicine and mechanical/traction therapy). However, several issues with these treatment options remain. While the improvement in $\mathrm{PC}$ with $\mathrm{CCH}$ is indisputable, its cost efficacy for all PD patients is not $(39,40)$. In the recent years, we have come to appreciate the complex spectrum of patients suffering from PD, there is an increased focus on pathophysiology, stage of disease, diagnostic evaluation and mental health [as previously mentioned, nearly $50 \%$ of PD patients experience depressive symptoms (4)]. Calculation of costs was performed by Cordon et al. (39), where they found that the total cost of penile plication amounts to $\$ 2,700$ on average, while $\mathrm{CCH}$ is considerably more expensive at $\$ 26,000$ in the US. They found that there was no cost-efficiency of $\mathrm{CCH}$ over plication for moderateto-severe curvature $\left(45-75^{\circ}\right)$. Importantly, the number of drop-outs due to adverse events, and the percentage of patients in whom $\mathrm{CCH}$ was able to prevent surgery was not specified in these studies. These trials also excluded any patients in the acute phase and having a calcified plaque, so the efficacy of $\mathrm{CCH}$ in these groups is not yet clear. In short, CCH injection is certainly not a "one size fits all" therapy and there remains a considerable gap for treatment of unresponsive patients, who can only undergo surgery to improve PC. In all, research for better medication (oral or intralesional) for PD is definitely not superfluous and should not be abandoned in the age of FDA/EMA approved CCH.
As it is no secret that developing new drugs from scratch is immensely expensive and time-consuming, up to 2.6 billion dollars and 15 years $(41,42)$, how can we work most efficiently towards discovery of novel drugs for PD?

The first drugs known in history have been recorded in the Ebers Papyrus (1500 BC) (43) and contains lists and combinations of plants thought to have therapeutic effects. Upon elucidating the active ingredient in some of these herbs in the 1800s, they became commonplace medicines. The father of modern drug discovery, Paul Ehrlich, began screening the effect of the newly discovered chemicals on biological systems. The molecular target and mechanism of action was uncovered only after the drug has been in use for several years/decades (phenotypic screening) (43). However, since the dawn of the genomic era in the 90s, drug discovery has usually started with a known molecular target. Typically, proteins that are thought to be principally involved in the disease pathogenesis (44). This target-centric approach has the benefit of providing a clear rationale, testable hypothesis and starting point, especially with the easy ultrahigh throughput computational recognition of perturbagens deducted from RNA sequencing data (virtual screening) (45). Both techniques have their advantages and disadvantages. Strengths of the target-based approach are the ability to test specific molecular hypotheses and the application of both small-molecule (possibility for high-throughput) and biological (monoclonal antibody)-based therapeutics. Its main weakness remains that certain molecular targets may not be as relevant for the disease process as previously thought. Phenotypic assays however do not require prior knowledge of the molecular mechanism of action, but challenges are the need for extensive optimization of the molecular properties and a significantly lower throughput (compared to target-based approaches). Table 1 provides an overview of studies utilising either a target-based approach or phenotypic screening in in vivo PD research.

\section{In vivo studies}

In 1982 Somers et al. (46) describe the first cell culture using fibroblasts from PD-derived plaques and compared them to normal penile TA tissue. Using transmission electron microscopy, they identified organized cytoplasmatic microfilament bundles and nuclear indentations in some PD-derived FBs, which highly resembled MFBs. Additionally, they grew to higher culture densities and had increased proliferative capacity compared to their nonPD counterparts. Although the latter was not confirmed in 


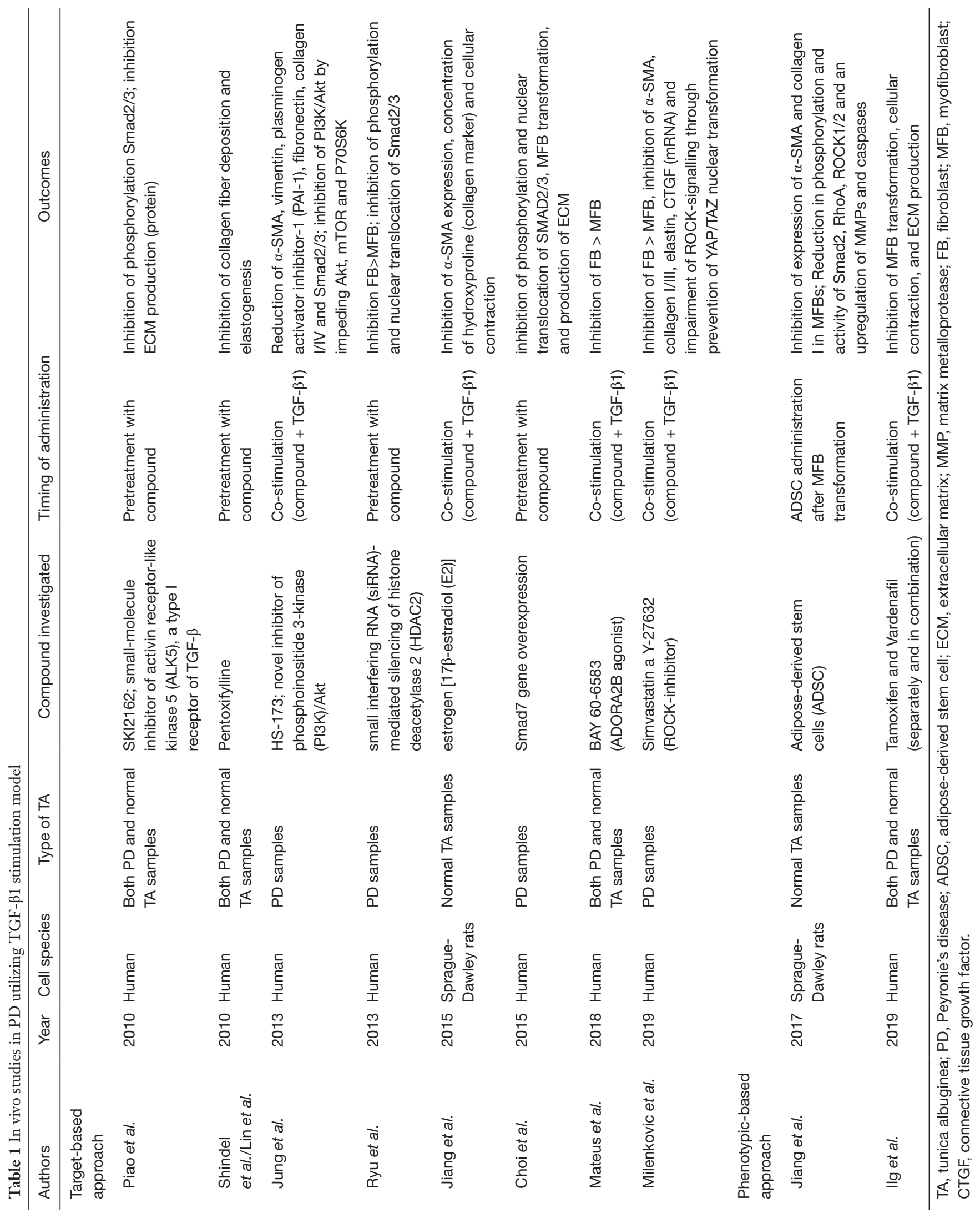


many recent studies $(8,30,47)$.

Independent of the type of organ afflicted, all fibrotic ailments have the MFB as a common denominator. The unique duality of MFBs makes them the most controversial cell type in normal and dysfunctional wound healing (48). This dual function consists of an ability to actively produce/ regulate the ECM whilst simultaneously acquiring contractile capacities similar to those of smooth muscle cells (SMCs) [both are $\alpha$-smooth muscle actin ( $\alpha$-SMA) positive] $(18,22,49-55)$. During the acute phase of tissue damage; mainly resident FBs (but other cell types as well) can experience a phenotypical switch to MFBs in an attempt to restore tissue integrity. The exact MFB precursor in PD and in fibrosis in general has been difficult to identify and stems either from epithelial/endothelial cells undergoing epithelial- or (I) endothelial-to-mesenchymal transition, or (II) a local aggregation of tissue-specific FBs, (III) peripheral blood-circulating fibrocytes (from bone marrow), (IV) local pool of mesenchymal stem cells (MSCs) or (V) SMCs $(1,56)$. In normal circumstances MFBs are either eliminated (apoptosis) or return to a quiescent state (57-60). When there is persisting injury however or when the apoptotic process is disturbed, this allows for the MFB to exert a significant amount of fibrosis and scar contraction (with subsequent curvature in $\mathrm{PD}$ or organ dysfunction on another organ fibrosis) $(48,61)$. A phenotypical switch towards the MFB cell type is marked by production of ECM-components such as collagens, elastin, fibronectin and connective tissue growth factor (CTGF), increased contractile ability, migration in response to chemotactic molecules, release of chemo-attractants for immune-related cells and contributing towards angiogenesis. Importantly, this process is mainly driven by activation TGF- $\beta 1$ and its downstream signalling $(57-60,62)$.

Subsequently, this led to TGF- $\beta 1$ stimulation of PDderived FBs representing the most commonly used PD in vivo model, introduced as early as 2002 by Lin et al. (63) and forms the basis of both the target-centric as well as the phenotypic screening approach. For example, it was shown that apart from MFB transformation and ECM production, TGF- $\beta 1$ also induced the expression of tissue inhibitors of metalloproteases (TIMPs), which inhibit the function of matrix metalloproteases (MMPs), which in turn are important for ECM breakdown (64). Moreover, TGF- $\beta 1$ was also able to induce $M C P-1$ gene expression, which is an important chemoattractant for cells of the innate immunity (65).

Concerning target-based approaches, many in vivo studies have focused on inhibition of the TGF- $\beta 1$ induced
MFB transformation and subsequent ECM production. Cell culture from normal TA or PD-plaques is established in a standardized way. Most protocols are based on tissue dissection with a scalpel, while ensuring no residual cavernosal tissue. Samples are cut into $3 \mathrm{~mm}^{3}$ segments and placed onto a Petri dish, while carefully adding conventional cell culture medium (with serum). The fragments are left undisturbed for 5-7 days in a standard incubation setup (humidified atmosphere, $37^{\circ} \mathrm{C}, 5 \% \mathrm{CO}_{2}$ ) to ensure $\mathrm{FB}$ attachment to the culture well. Once FB growth is established the tissue fragments are removed, and medium changed frequently, after which the cells are expanded further. It is recommended to use cells of early passages (P2-7) for further experimentation, as they are prone to transcriptional and chromosomal changes during higher passages (66).

In 2010, Piao et al. (67) found that adding a TGF- $\beta$ type I receptor kinase (ALK5) inhibitor (SKI2162) prior to TGF- $\beta 1$ prevented intracellular signalling (through the protein class of mothers against decapentaplegic homologs (Smad)] and decreased production of ECM proteins. Similar outcome parameters were used by Lin et al. and Shindel et al. $(68,69)$ where they assessed the effects of pentoxifylline (PTX) on TGF- $\beta 1$ dependent collagen- and elastogenesis. In their experimental set-up TGF- $\beta 1$ stimulated elastogenesis and collagen I production in FBs in both a dose- and time-dependent fashion. Pretreatment with PTX drastically impaired TGF- $\beta 1$-mediated elastogenesis and collagen deposition in FBs (derived from patients with and without PD). Jung et al. (70) investigated the role of HS-173, a novel inhibitor of phosphoinositide 3-kinase (PI3K)/Akt signalling in TGF- $\beta 1$ stimulated FBs. HS-173 reduced the expression of $\alpha$-SMA, vimentin, plasminogen activator inhibitor-1 (PAI-1), fibronectin, collagen I, collagen IV and TGF- $\beta$-activated $\operatorname{smad} 2 / 3$ in PDderived primary FBs. Ryu and colleagues (71) proposed that pre-treatment of human PD-derived FBs with a small interfering (si)RNA-mediated histone deacetylase 2 (HDAC2)-silencer could offer an antifibrotic effect. Knock-down of HDAC2 impeded TGF- $\beta 1$ induced ECM production in a Smad-dependent manner and was able to inhibit MFB transformation entirely. In 2015, Jiang et al. (72) assessed whether estrogen [17 $\beta$-estradiol (E2)] could suppress the differentiation of primary rat TA-derived FBs into MFBs in vivo. They uncovered that E2 was able to inhibit TGF- $\beta 1$ induced $\alpha$-SMA expression, concentration of hydroxyproline (collagen marker) and cellular contraction. Mechanistically these effects occurred 
through inhibition of both canonical Smad intracellular signalling and Rho-associated coiled-coil containing protein kinase 2 (ROCK2). Choi et al. (73) set out to investigate the effect of Smad7 (an inhibitory Smad protein that blocks the TGF- $\beta$ signalling) on PD-derived FBs. Pretreatment of these cells with Smad7 gene and exposure to TGF- $\beta 1$ afterwards inhibited TGF- $\beta 1$-induced phosphorylation and nuclear translocation of Smad2/3, MFB transformation, and abrogated TGF- $\beta 1$-induced production of ECM. Moreover, Smad7 overexpression decreased the expression of cyclin D1 (a positive cell cycle regulator) and induced the expression of polypolymerase-1, which terminates Smadmediated transcription.

Further, Mateus et al. (30) researched the role of adenosine receptors in TGF- $\beta 1$ MFB transformation. They found that two out of four adenosine receptors (ADORA1 and ADORA2B) were expressed in PD- and TA-derived cells. BAY 60-6583, an ADORA2B agonist, was able to significantly inhibit MFB transformation in a dose-dependent manner when applied simultaneously with TGF- $\beta 1$. Lastly, in a study by our group (31) the effects of simvastatin and Y-27632, a pan-ROCK-inhibitor, on TGF$\beta 1$-induced MFB transition was investigated. PD-patient derived FBs were subjected to either vehicle, TGF- $\beta 1$ only, TGF- $\beta 1+$ simvastatin or TGF- $\beta 1+\mathrm{Y}-27632$ in various concentrations. It was shown that administration of Y-27632 and simvastatin was able to prevent TGF- $\beta 1$ induced FB to MFB transformation and subsequent transcription of profibrotic genes such as $\alpha$-SMA, collagens, elastin and CTGF. While the effect of Y-27632 and simvastatin on ECM and contractility was not formally examined, inhibition of MFB transformation on an mRNA and protein level and ECM production on an mRNA level was evidenced. Combining these findings, it can be deduced that these cells were not contractile and produced less ECM. It was also shown that both molecules inhibited YAP/TAZ nuclear translocation, which suggests that ROCK-signalling was indeed impaired. Since ROCK is essential for actin polymerization and myosine light chain phosphatase inhibition, this suggests further that cellular contraction was inhibited. Moreover, YAP/TAZ is an important profibrotic transcription factor and the prevention of its nucleic activity suggests attenuated ECM production as well. ROCK-inhibitors can prove to be particularly promising for early stage PD. In human tissue, ROCK inhibition results in human CC relaxation (74). One could imagine the effectiveness of intralesional injection of ROCK inhibitors for patients suffering from PD and ED (occurring in about $50 \%$ of PD patients), by simultaneously tackling both their ailments $(3,74)$.

Phenotypic-based approaches can either be interpreted as phenotypical screening assays or as regenerative medicine approaches, where substances (such as MSCs, stromal vascular fraction and platelet-rich plasma) are administered to obtain an antifibrotic phenotype/condition, without the mechanism of action being precisely elucidated.

Recently, using high-throughput methodology Ilg et al. (8) had screened 21 compounds that were previously suggested as antifibrotic treatments in $\mathrm{PD}$, but never made it to clinical practice due to several limitations, not in the least due to inadequate dosing and single arm study design. Using in-cell ELISA (ICE) in the TGF- $\beta 1$ based in vivo model, they had identified phosphodiesterase 5 -inhibitors (PDE5is) and selective oestrogen receptor modulators (SERMs) as antifibrotic (inhibition of MFB transformation, cellular contraction, and ECM production) in a synergistic manner. Additionally, this hypothesis was tested in vivo in the rat model of PD in order to investigate if this synergistic effect can be observed in animals as well. The rat model of PD consists of injecting TGF- $\beta 1$ into the rat TA. A fibrotic plaque develops approximately 4-6 weeks after injection. Upon molecular investigation there was an increased amount of elastin, collagen I and III in the plaques compared to the SMC-content. Moreover, like in the human situation, these rats have marked ED as measured by intracavernosal pressure measurement after cavernosal nerve stimulation. The 2 drugs appeared to work synergistically to restore elastin protein levels. Additionally, administration of tamoxifen, vardenafil or the combination restored erectile function in these rats as well.

Second, regenerative medicine has known a surge in popularity over the past decade and not in the least for applications in sexual medicine, most notably ED and PD. Stem cells are capable of self-renewal and their potential for differentiation can give rise to more mature cell populations. MSCs work in a paracrine fashion, have many immunomodulatory functions, can escape the host immune system and switch between their pro- and antiinflammatory phenotypes depending on the local tissue environment. In 2017, Jiang et al. (75) tested the inhibitory effects and possible mechanism of action of adipose-derived stem cells (ADSC) in rat TA-derived FBs. FBs were first treated with TGF- $\beta 1$ and a co-culture between MFBs and ADSCs was set-up using Transwell. ADSC attenuated the expression of $\alpha$-SMA and collagen I in MFBs. Moreover, there was a reduction in phosphorylation and activity of Smad2, RhoA, ROCK1/2 and an upregulation of MMPs 
and caspases in the co-culture compared to the MFB-only set-up. Interestingly, injection of ADSCs, their lysate or stromal vascular fraction in a TGF- $\beta 1$-based rat model of PD has proven to be an effective method of fibrosis alleviation in many in vivo studies (76-80). Even though there are some studies that have investigated the use of MSCs in PD in preclinical in vivo studies, their precise mechanism of action was not investigated, despite managing to show an antifibrotic effect on PD plaque and restoration of erectile function $(76,77)$. These have been discussed extensively in other studies $(1,81)$ and are beyond the scope of this manuscript.

\section{Potential of in vivo models}

As previously mentioned, the rat model of PD consists of injecting TGF- $\beta 1$ into the rat TA. Even though this mimics the human disease in terms of ED and fibrosis, it does not have its hallmark feature of PC and ossification. Moreover, this model relies on the administration of an "acute", single trauma, while PD develops through chronic and repetitive buckling and damaging of the TA. Other inconsistencies of this model include the fact that the plaque is self-limiting with spontaneous resolution in rats and inconsistency in the plaque duration and formation across studies $(78,82)$.

Other animal models include the injection of fibrin, thrombin and repeated injection of TGF- $\beta 1$-carrying adenovirus into the rat TA (82). However, injection and preparation of these products is cumbersome and offer no added advantage compared to the TGF- $\beta 1$ model. The only genetic mouse model for PD [tight skinned (Tsk)] is based on a tandem duplication of the fibrillin-1 gene and subsequent upregulation of hypoxia-inducible factor-1 (HIF-1) (83). This Tsk mouse model develops a PD-like plaque in the mouse penis with spontaneous curvature and plaque ossification, over the span of 12 months. However, due to the fact that disease progression occurs over 12 months, testing of drugs countering the fibrosis remains very time consuming and expensive. Moreover, this genetic model does not only cause PD-like lesions, but also varying forms of systemic sclerosis, further limiting its use.

Future genetic models should provide the development of a PD-like plaque, with ED and curvature, occurring over a relatively short period of time. This would allow for improved drug testing and increase the feasibility of optimizing the dosage, route of administration and combination of drugs before translation into clinical trials.

\section{Future research}

Despite the establishment of MFB as one of the key cell types involved in PD and despite a large amount of in vivo (and in vivo) research focused on preventing/reversing this phenotype, there have been very little advances in the nonsurgical treatment of PD.

It is important to note that myofibroblasts and ECM do not exist in a vacuum and several other cell types can influence their survival, function and remodelling (84). For example, the ECM is not just a scaffold for MFBs, but it deeply affects the initiation and maintenance of the proinflammatory and profibrotic process (85). Not only does it activate various precursors into MFB independently (through transduction of mechanical forces) and releases latent TGF- $\beta 1$ stores (6), it also provides a "railway" for incoming inflammatory cells (mostly macrophages and dendritic cells) in the initial stages. Macrophages are attracted to the inflammatory site either through chemotactic molecules such as MCP-1 or through physical "tugging" from the MFBs (84).

As such, there is a need to look beyond the terminal role of the MFB and further characterize the role immune cells involved in driving this chronic fibrosis (57). To achieve a better insight into genes and pathways that drive PD, recent investigations by our group performed an in-depth analysis of the transcriptome of PD human samples using high-throughput RNA sequencing (unpublished data). Gene ontology revealed a protracted active inflammation component in these chronic plaques, while it was previously believed that inflammation terminates when the plaque stabilizes. Cross-referencing gene set enrichment analysis results with transcriptional regulation analysis showed the most significantly enriched pathways to be; nuclear factor kappa-light-chain-enhancer of activated B cells (NF-kB) [tumour necrosis factor $\alpha(\mathrm{TNF} \alpha)$ and Toll-like receptors (TLR)-activated) and Janus kinases (JAK)/signal transducer and activator of transcription proteins (STAT)-signalling (through interleukins/interferons)]. Based on this, we hypothesized that cells of the innate immunity are essential for PD-related fibrosis, which connects to the "trauma/ mechanical stress" model (86). A variety of mediators (DAMPs, PAMPs, growth factors, cytokines) released in the local tissue micro-environment during stress situations, are recognized by TLRs on precursor myeloid cells (87). This role of the (innate) immune system has also been suggested over 20 years ago by Ralph et al. (88) where they were able to identify a population of macrophages and T-cell within 
the active plaque.

It is clear that fibrosis is a complex disease containing an interaction of many cell types (FBs, MFBs, endothelial cells, stem cells and cells of the innate and adaptive immunity). Previous in vivo studies in PD have failed to address this complexity and have only targeted the (M)FB and only one pathway (TGF- $\beta 1$ ) in most cases. It has been shown in other fibrotic diseases that attenuating one part of the inflammatory and fibrotic cascade leads to activation of a flurry of compensatory mechanisms (89), as it is an ancient pathway, necessary for survival. Despite some marked progress in $\mathrm{PD}$ research during recent years, we will need to develop more disease-relevant in vivo (and possibly in vivo) models in order to bring PD research into the next gear. Development of co-culture systems, collagen scaffolds and $3 \mathrm{D}$ culturing models where immune cells are involved as well would mimic the true disease situation more accurately. Moreover, further characterisation of human plaques using novel single cell sequencing can offer a unique view on the human plaque. Applying the high-throughput methodology as used by Ilg et al. on these novel culturing systems could provide the much-needed missing link in the medical treatment of PD. Finally, currently available FDA-approved conservative treatment options such as intralesional $\mathrm{CCH}$ need to be better tailored for use in patients who have the largest chance to respond.

\section{Conclusions}

Even though significant research efforts have already been allocated to unravelling the complex pathophysiology of $\mathrm{PD}$, an increase in public and industrial awareness is sorely needed. Current in vivo models have been an excellent stepping stone for testing hypotheses, but their relative lack of success means we have to develop novel methods to investigate PD. High-throughput screening and next-generation sequencing can offer a unique and unprecedented outlook, which could facilitate the translation of potential drugs into clinical trials.

\section{Acknowledgments}

Funding: None.

\section{Footnote}

Provenance and Peer Review: This article was commissioned by the Guest Editors (Larry I. Lipshultz, Alexander W. Pastuszak) for the focused issue "Contemporary Issues and Controversies in Men's Health" published in Translational Andrology and Urology. The article was sent for external peer review organized by the Guest Editors and the editorial office.

Conflicts of Interest: The focused issue "Contemporary Issues and Controversies in Men's Health" was commissioned by the editorial office without any funding or sponsorship. The authors have no conflicts of interest to declare.

Ethical Statement: The authors are accountable for all aspects of the work in ensuring that questions related to the accuracy or integrity of any part of the work are appropriately investigated and resolved.

Open Access Statement: This is an Open Access article distributed in accordance with the Creative Commons Attribution-NonCommercial-NoDerivs 4.0 International License (CC BY-NC-ND 4.0), which permits the noncommercial replication and distribution of the article with the strict proviso that no changes or edits are made and the original work is properly cited (including links to both the formal publication through the relevant DOI and the license). See: https://creativecommons.org/licenses/by-nc$\mathrm{nd} / 4.0 \%$.

\section{References}

1. Milenkovic U, Albersen M, Castiglione F. The mechanisms and potential of stem cell therapy for penile fibrosis. Nat Rev Urol 2019;16:79-97.

2. Hellstrom WJG, Feldman R, Rosen RC, et al. Bother and distress associated with Peyronie's disease: validation of the Peyronie's disease questionnaire. J Urol 2013;190:627-34.

3. Milenkovic U, Campbell J, Roussel E, et al. An update on emerging drugs for the treatment of erectile dysfunction. Expert Opin Emerg Drugs 2018;23:319-30.

4. Nelson CJ, Diblasio C, Kendirci M, et al. The chronology of depression and distress in men with peyronie's disease. J Sex Med 2008;5:1985-90.

5. Devine CJJ, Somers KD, Jordan GH, et al. Proposal: Trauma as the Cause of the Peyronie's Lesion. J Urol 1997;157:285-90.

6. Hinz B. The extracellular matrix and transforming growth factor- $\beta 1$ : Tale of a strained relationship. Matrix Biol 2015;47:54-65.

7. Gonzalez-Cadavid NF, Rajfer J. Mechanisms of Disease: new insights into the cellular and molecular pathology of 
Peyronie's disease. Nat Clin Pract Urol 2005;2:291-7.

8. Ilg MM, Mateus M, Stebbeds WJ, et al. Antifibrotic Synergy Between Phosphodiesterase Type 5 Inhibitors and Selective Oestrogen Receptor Modulators in Peyronie's Disease Models. Eur Urol 2019;75:329-40.

9. Milenkovic U, Ilg MM, Cellek S, et al. Pathophysiology and Future Therapeutic Perspectives for Resolving Fibrosis in Peyronie's Disease. Sex Med Rev 2019. [Epub ahead of print].

10. Russo GI, Milenkovic U, Hellstrom W, et al. Clinical Efficacy of Injection and Mechanical Therapy for Peyronie's Disease: A Systematic Review of the LiteratureFigure presented]. Eur Urol 2018. doi:10.1016/ j.eururo.2018.07.005.

11. Gonzalez-Cadavid NF. Mechanisms of penile fibrosis. J Sex Med 2009;6 Suppl 3:353-62.

12. Tsambarlis P, Levine LA. Nonsurgical management of Peyronie's disease. Nat Rev Urol 2019;16:172-86.

13. Gelbard M, Goldstein I, Hellstrom WJG, et al. Clinical Efficacy, Safety and Tolerability of Collagenase Clostridium Histolyticum for the Treatment of Peyronie Disease in 2 Large Double-Blind, Randomized, Placebo Controlled Phase 3 Studies. J Urol 2013;190:199-207.

14. Tsambarlis PN, Yong R, Levine LA. Limited success with clostridium collagenase histolyticum following FDA approval for the treatment of Peyronie's disease. Int J Impot Res 2019;31:15-9.

15. Cohen IK. The Evolution of Wound Healing. Totowa, NJ: Humana Press, 2006:51-7.

16. Janeway C. Immunobiology 5: the immune system in health and disease. New York: Garland Pub, 2001.

17. Castella LF, Buscemi L, Godbout C, et al. A new lock-step mechanism of matrix remodelling based on subcellular contractile events. J Cell Sci 2010;123:1751-60.

18. Rockey DC, Bell PD, Hill JA. Fibrosis - A Common Pathway to Organ Injury and Failure. N Engl J Med 2015;372:1138-49.

19. Vannella KM, Wynn TA. Mechanisms of Organ Injury and Repair by Macrophages. Annu Rev Physiol 2017;79:593-617.

20. Wynn TA. Common and unique mechanisms regulate fibrosis in various fibroproliferative diseases. J Clin Invest 2007;117:524-9.

21. Wynn TA. Cellular and molecular mechanisms of fibrosis. J Pathol 2008;214:199-210.

22. Wynn TA. Mechanism of fibrosis: therapeutic translation for fibrotic disease. Nat Med 2012;18:1028-40.

23. Cannito S, Novo E, Parola M. Therapeutic pro-fibrogenic signaling pathways in fibroblasts. Adv Drug Deliv Rev 2017;121:57-84.

24. Mohede DCJ, de Jong IJ, van Driel MF. Medical Treatments of Peyronie's Disease: Past, Present, and Future. Urology 2019;125:1-5.

25. El-Sakka AI, Hassoba HM, Chui RM, et al. An animal model of Peyronie's-like condition associated with an increase of transforming growth factor beta mRNA and protein expression. J Urol 1997;158:2284-90.

26. El-Sakka AI, Hassan MU, Nunes L, et al. Histological and ultrastructural alterations in an animal model of Peyronie's disease. Br J Urol 1998;81:445-52.

27. Vernet D, Ferrini MG, Valente EG, et al. Effect of nitric oxide on the differentiation of fibroblasts into myofibroblasts in the Peyronie's fibrotic plaque and in its rat model. Nitric Oxide 2002;7:262-76.

28. Mulhall JP, Anderson MS, Lubrano T, et al. Peyronie's disease cell culture models: phenotypic, genotypic and functional analyses. Int J Impot Res 2002;14:397-405.

29. Valente EGA, Vernet D, Ferrini MG, et al. L-Arginine and phosphodiesterase (PDE) inhibitors counteract fibrosis in the Peyronie's fibrotic plaque and related fibroblast cultures. Nitric Oxide 2003;9:229-44.

30. Mateus M, Ilg MM, Stebbeds WJ, et al. Understanding the Role of Adenosine Receptors in the Myofibroblast Transformation in Peyronie's Disease. J Sex Med 2018;15:947-57.

31. Milenkovic U, Ilg MM, Zuccato C, et al. Simvastatin and the Rho-kinase inhibitor Y-27632 prevent myofibroblast transformation in Peyronie's disease-derived fibroblasts via inhibition of YAP/TAZ nuclear translocation. BJU Int 2019;123:703-15.

32. Gonzalez-Cadavid NF, Rajfer J. Molecular pathophysiology and gene therapy of aging-related erectile dysfunction. Exp Gerontol 2004;39:1705-12.

33. Intengan HD, Schiffrin EL. Vascular remodeling in hypertension: roles of apoptosis, inflammation, and fibrosis. Hypertension 2001;38:581-7.

34. Becker GJ, Perkovic V, Hewitson TD. Pharmacological intervention in renal fibrosis and vascular sclerosis. J Nephrol 2001;14:332-9.

35. Gholami SS, Gonzalez-Cadavid NF, Lin CS, et al. Peyronie's Disease: A Review. J Urol 2003;169:1234-41.

36. Rhoden EL, Teloken C, Ting HY, et al. Prevalence of Peyronie's disease in men over 50-y-old from Southern Brazil. Int J Impot Res 2001;13:291-3.

37. Hellstrom WJG. History, epidemiology, and clinical presentation of Peyronie's disease. Int J Impot Res 
2003;15:S91.

38. Getting the facts straight about Peyronie's. BMI Healthcare UK. Available online: https://www.bmihealthcare.co.uk/ health-matters/mens-health/peyronies-disease

39. Cordon BH, Hofer MD, Hutchinson RC, et al. Superior Cost Effectiveness of Penile Plication vs Intralesional Collagenase Injection for Treatment of Peyronie's Disease Deformities. Available online: https://www.auajournals. org/doi/full/10.1016/j.urpr.2016.04.005

40. Wayne GF, Cordon BH. Contemporary surgical and nonsurgical management of Peyronie's disease. Transl Androl Urol 2018;7:603-17.

41. Sullivan Thomas. A Tough Road: Cost To Develop One New Drug Is \$2.6 Billion; Approval Rate for Drugs Entering Clinical Development is Less Than 12\% - Policy \&amp; Medicine. Available online: https://www.policymed. com/2014/12/a-tough-road-cost-to-develop-one-newdrug-is-26-billion-approval-rate-for-drugs-enteringclinical-de.html

42. Mullard A. On the origin of transformative drugs. Nat Rev Drug Discov 2018;17:385.

43. Spector JM, Harrison RS, Fishman MC. Fundamental science behind today's important medicines. Sci Transl Med 2018;10:eaaq1787.

44. Overington JP, Al-Lazikani B, Hopkins AL. How many drug targets are there? Nat Rev Drug Discov 2006;5:993-6.

45. Subramanian A, Narayan R, Corsello SM, et al. RESOURCE A Next Generation Connectivity Map: L1000 platform and the first 1,000,000 profiles 2017. Cell 2017;171:1437-52.e17.

46. Somers KD, Dawson DM, Wright GL, et al. Cell culture of Peyronie's disease plaque and normal penile tissue. J Urol 1982;127:585-8.

47. Anderson MS, Shankey TV, Lubrano T, et al. Inhibition of Peyronie's plaque fibroblast proliferation by biologic agents. Int J Impot Res 2000;12 Suppl 3:S25-31.

48. Hinz B, Phan SH, Thannickal VJ, et al. The myofibroblast: one function, multiple origins. Am J Pathol 2007;170:1807-16.

49. Duffield JS, Lupher M, Thannickal VJ, et al. Host Responses in Tissue Repair and Fibrosis. Annu Rev Pathol 2013;8:241-76.

50. Lee YA, Wallace MC, Friedman SL. Pathobiology of liver fibrosis: a translational success story. Gut 2015;64:830-41.

51. Trautwein C, Friedman SL, Schuppan D, et al. Hepatic fibrosis: Concept to treatment. J Hepatol 2015;62:S15-24.

52. Seki E, Schwabe RF. Hepatic inflammation and fibrosis: functional links and key pathways. Hepatology
2015;61:1066-79.

53. Noble PW, Barkauskas CE, Jiang D. Pulmonary fibrosis: patterns and perpetrators. J Clin Invest 2012;122:2756-62.

54. Smith ML. Update on Pulmonary Fibrosis: Not All Fibrosis Is Created Equally. Arch Pathol Lab Med 2016;140:221-9.

55. Liu Y. Cellular and molecular mechanisms of renal fibrosis. Nat Rev Nephrol 2011;7:684-96.

56. McAnulty RJ. Fibroblasts and myofibroblasts: Their source, function and role in disease. Int J Biochem Cell Biol 2007;39:666-71.

57. Novo E, Cannito S, Paternostro C, et al. Cellular and molecular mechanisms in liver fibrogenesis. Arch Biochem Biophys 2014;548:20-37.

58. Parola M, Marra F, Pinzani M. Myofibroblast - like cells and liver fibrogenesis: Emerging concepts in a rapidly moving scenario. Mol Aspects Med 2008;29:58-66.

59. Fernández M, Semela D, Bruix J, et al. Angiogenesis in liver disease. J Hepatol 2009;50:604-20.

60. Gonzalez-Cadavid NF, Rajfer J. Experimental models of peyronie's disease. Implications for new therapies. J Sex Med 2009;6:303-13.

61. Hinz B, Phan SH, Thannickal VJ, et al. Recent Developments in Myofibroblast Biology. Am J Pathol 2012;180:1340-55.

62. Cannito S, Novo E, Parola M. Therapeutic pro-fibrogenic signaling pathways in fibroblasts. Adv Drug Deliv Rev 2017;121:57-84.

63. Lin CS, Lin G, Wang Z, et al. Upregulation of monocyte chemoattractant protein 1 and effects of transforming growth factor- $\beta 1$ in Peyronie's disease. Biochem Biophys Res Commun 2002;295:1014-9.

64. Del Carlo M, Cole AA, Levine LA. Differential Calcium Independent Regulation of Matrix Metalloproteinases and Tissue Inhibitors of Matrix Metalloproteinases by Interleukin- $1 \beta$ and Transforming Growth Factor- $\beta$ in Peyronie's Plaque Fibroblasts. J Urol 2008;179:2447-55.

65. Szardening-Kirchner C, Konrad L, Hauck EW, et al. Upregulation of mRNA expression of MCP-1 by TGF- $\beta 1$ in fibroblast cells from Peyronie's disease. World J Urol 2009;27:123-30.

66. Mulhall JP, Nicholson B, Pierpaoli S, et al. Chromosomal instability is demonstrated by fibroblasts derived from the tunica of men with Peyronie's disease. Int J Impot Res 2004;16:288-93.

67. Piao S, Choi MJ, Tumurbaatar M, et al. Transforming Growth Factor (TGF)- $\beta$ Type I Receptor Kinase (ALK5) Inhibitor Alleviates Profibrotic TGF- $\beta 1$ Responses in 
Fibroblasts Derived from Peyronie's Plaque. J Sex Med 2010;7:3385-95.

68. Lin G, Shindel AW, Banie L, et al. Pentoxifylline attenuates transforming growth factor-beta1-stimulated elastogenesis in human tunica albuginea-derived fibroblasts part 2: Interference in a TGF-beta1/Smad-dependent mechanism and downregulation of AAT1. J Sex Med 2010;7:1787-97.

69. Shindel AW, Lin G, Ning H, et al. Pentoxifylline attenuates transforming growth factor- $\beta 1$-stimulated collagen deposition and elastogenesis in human tunica albuginea-derived fibroblasts part 1: Impact on extracellular matrix. J Sex Med 2010;7:2077-85.

70. Jung KH, Ryu YL, Lee HS, et al. A novel PI3K inhibitor alleviates fibrotic responses in fibroblasts derived from Peyronie's plaques. Int J Oncol 2013;42:2001-8.

71. Ryu JK, Kim WJ, Choi MJ, et al. Inhibition of histone deacetylase 2 mitigates profibrotic TGF-beta 1 responses in fibroblasts derived from Peyronie's plaque. Asian J Androl 2013;15:640-5.

72. Jiang HS, Zhu LL, Zhang Z, et al. Estradiol attenuates the TGF- $\beta 1$-induced conversion of primary TAFs into myofibroblasts and inhibits collagen production and myofibroblast contraction by modulating the Smad and Rho/ROCK signaling pathways. Int J Mol Med 2015;36:801-7.

73. Choi MJ, Song KM, Park JM, et al. Effect of SMAD7 gene overexpression on TGF- $\beta 1$-induced profibrotic responses in fibroblasts derived from Peyronie's plaque. Asian J Androl 2015;17:487-92.

74. Uvin P, Albersen M, Bollen I, et al. Additive effects of the Rho kinase inhibitor Y-27632 and vardenafil on relaxation of the corpus cavernosum tissue of patients with erectile dysfunction and clinical phosphodiesterase type 5 inhibitor failure. BJU Int 2017;119:325-32.

75. Jiang H, Gao Q, Che X, et al. Inhibition of penile tunica albuginea myofibroblasts activity by adipose-derived stem cells. Exp Ther Med 2017;14:5149-56.

76. Castiglione F, Hedlund P, Van der Aa F, et al. Intratunical injection of human adipose tissue-derived stem cells prevents fibrosis and is associated with improved erectile function in a rat model of Peyronie's disease. Eur Urol 2013;63:551-60.

77. Castiglione F, Hedlund P, Weyne E, et al. Intratunical Injection of Human Adipose Tissue-Derived Stem Cells Restores Collagen III/I Ratio in a Rat Model of Chronic Peyronie's Disease. Sex Med 2019;7:94-103.

78. Castiglione F, Hedlund P, Weyne EE, et al. Intratunical
Injection of Stromal vascular fraction prevents Fibrosis in a Rat Model of Peyronie's Disease. BJU Int 2019;124:342-8.

79. Hakim L, Fiorenzo S, Hedlund P, et al. Intratunical injection of autologous adipose stromal vascular fraction reduces collagen III expression in a rat model of chronic penile fibrosis. Int J Impot Res 2019. [Epub ahead of print].

80. Gokce A, Abd Elmageed ZY, Lasker GF, et al. Adipose tissue-derived stem cell therapy for prevention and treatment of erectile dysfunction in a rat model of Peyronie's disease. Andrology 2014;2:244-51.

81. Soebadi MA, Milenkovic U, Weyne E, et al. Stem Cells in Male Sexual Dysfunction: Are We Getting Somewhere? Sex Med Rev 2017;5:222-35.

82. Chung E, De Young L, Brock GB. Rat as an animal model for Peyronie's disease research: a review of current methods and the peer-reviewed literature. Int J Impot Res 2011;23:235-41.

83. Lucattelli M, Lunghi B, Fineschi S, et al. A new mouse model of Peyronie's disease: An increased expression of hypoxia-inducible factor- 1 target genes during the development of penile changes. Int J Biochem Cell Biol 2008;40:2638-48.

84. Pakshir P, Hinz B. The big five in fibrosis: Macrophages, myofibroblasts, matrix, mechanics, and miscommunication. Matrix Biol 2018;68-69:81-93.

85. Klingberg F, Hinz B, White ES. The myofibroblast matrix: implications for tissue repair and fibrosis. J Pathol 2013;229:298-309.

86. Lawrence $\mathrm{T}$. The nuclear factor NF-kappaB pathway in inflammation. Cold Spring Harb Perspect Biol 2009;1:a001651.

87. Land WG. The Role of Damage-Associated Molecular Patterns (DAMPs) in Human Diseases: Part II: DAMPs as diagnostics, prognostics and therapeutics in clinical medicine. Sultan Qaboos Univ Med J 2015;15:e157-70.

88. Ralph DJ, Mirakian R, Pryor JP, et al. The Immunological Features of Peyronie's Disease. J Urol 1996;155:159-62.

89. Milenkovic U, Ilg M, Cellek S, et al. What role do pharmaceuticals play in the treatment of Peyronie's disease and is there a need for new emerging drugs? Expert Opin Emerg Drugs 2019;24:1-4.

Cite this article as: Milenkovic U, Duponselle J, Bivalacqua TJ, Albersen M. Evolving therapies for Peyronie's disease: how can we work towards new drugs? Transl Androl Urol 2020;9(Suppl 2):S284-S294. doi: 10.21037/tau.2019.08.09 